\title{
Capacity Assessment of Rectangular Concrete-Filled Steel Tube (RCFT) Members and Connections for Performance-Based Design of Composite Frames
}

\author{
Cenk Tort ${ }^{1}$ and Jerome F. Hajjar ${ }^{2}$ \\ ${ }^{1}$ Graduate Research Assistant, Department of Civil Engineering, 500 Pillsbury Drive \\ SE, University of Minnesota, Minneapolis, MN 55455. \\ ${ }^{2}$ Professor, Department of Civil Engineering, 500 Pillsbury Drive SE, University of \\ Minnesota, Minneapolis, MN 55455, email: hajjar@struc.ce.umn.edu
}

\section{Abstract}

This paper presents research documenting the local damage progression in rectangular concrete-filled steel tube beam-columns and connections in composite frames. Local damage is quantified through the development of damage indices based upon results of worldwide experiments. A fiber-based finite element formulation is also introduced for assessing global capacity and seismic demand.

\section{Introduction}

The lessons learned from the past earthquakes have initiated a motivation in research and practice to augment conventional strength-based seismic design codes for buildings with procedures that predict damage for a broader range of earthquakes. In Performance-Based Design (PBD), multiple performance objectives may be defined. Each performance objective describes the damaged state of the structure for a prescribed level of seismic loading. PBD thus provides guidelines for engineers to design for each of the performance objectives (Moehle and Deierlein, 2004). The full advantage of PBD is utilized if it is implemented in a probabilistic framework. This allows for the inherent uncertainty and randomness in seismic design so that the engineers have the capability of quantifying the reliability of their designs.

Development of PBD guidelines may be realized through definition and quantification of four main components listed below (Moehle and Deierlein, 2004):

- Intensity Measure (IM)

- Engineering Demand Parameter (EDP)

- Damage Measures (DM)

- Decision Variables (DV)

IM is the parameter representing the intensity level of ground motions (e.g., first mode spectral acceleration, peak ground acceleration). EDP characterizes the structural response during an earthquake. The most widely used EDPs include quantities such as maximum interstory drift, base-shear, and dissipated hysteretic energy. DMs describe the damaged state of the structure and its components such as 
local buckling, concrete crushing, residual drift, etc. DVs are the parameters defining the structural performance in a format that most interests the decision makers. The DVs are often expressed in terms of casualty rate, down time, and repair cost.

Capacity assessment of structures is considered as one of the main tools to identify the four components of PBD described above. First, the EDPs need to be selected from structural response parameters that adequately represent the capacity. Second, the link between EDPs and DMs must be developed with a solid understanding of capacity of the structure and its components. Third, the selection of repair techniques to be applied is governed by the available capacity of structures. Therefore, capacity assessment is also critical in defining DVs.

The focus of this study is to develop PBD methodologies for composite structures, with a focus on rectangular concrete-filled steel tubes (RCFTs) in composite frame structures consisting of steel girders framing into RCFT beam-columns (Tort and Hajjar, 2003, 2004). This paper reports the first stage of that research, including establishing the DMs for RCFTs based upon the experimental capacity of RCFT members, connections, and frames. The paper then describes a new fiber-based beam-column finite element formulation, including new constitutive rules for steel and concrete in RCFTs, which will be used to assess global capacity and predict seismic demand in RCFT frames.

\section{Capacity Assessment at the Local Level}

Experimental tests conducted on RCFT members and connections provide the required data to investigate their capacity and document the associated damage measures. In this research, the experimental results were quantified in a unified format using deformation-based and energy-based damage functions.

\section{Development of Experimental Database}

Six databases were constructed for RCFT members including columns, beamcolumns, panel zones, pinned connections, moment-resisting connections, and frames. Both monotonically and cyclically loaded components were studied where tests were available. The experimental tests existing in the literature were carefully examined and only well documented tests in which the progression of damage was quantifiable were included. Specimens were limited to those manufactured from cold-formed steel tubes. The information presented in the database was grouped into four sections, description of the test, material properties, geometric properties, and experimental results. The tests were described by reporting the boundary conditions and loading scheme applied to the specimens. The material strengths (compressive strength of concrete, $f^{\prime}{ }_{c}$, yield strength of steel tube, $f_{y}$, modulus of elasticity of steel tube, $E_{s}$ ) and specimen dimensions (depth, $D$, width, $B$, thickness, $t$, length, $L$ ) were provided in terms of both nominal and measured values. The experimental results included peak strength and displacement values, failure patterns, and local damage levels recorded in terms of the force and deformation values at the occurrence of the local damage state. 


\section{Damage Assessment}

In PBD, various damage states identifying the progression of structural damage are defined. These damage states may then be related to the performance objectives of the structural components. For RCFT members, the limit states were identified as local damage levels occurring in the steel tube, concrete core, or connection components. The common local damage levels observed in RCFT beamcolumns during the tests were concrete cracking, yielding of steel tube, concrete crushing, local buckling of the steel tube, and fracture of the steel tube. Corresponding damage states were identified for the connection components (Tort and Hajjar, 2003). The occurrence of these local damage levels were quantified with the use of damage functions where force and deformation values were used as the operating variables. Two types of damage functions were defined. The deformationbased damage function $(\hat{D})$ is defined as the ratio of the deformation at the occurrence of local damage $\left(d_{c u r r}\right)$ to the deflection attained when the peak load is reached $\left(d_{o}\right)$ (with the specific type of load and deflection being assessed varying with the type of test) as given in Equation 1:

$$
\hat{D}=d_{\text {curr }} / d_{o}
$$

The energy-based damage function $(\hat{E})$ is defined as the ratio of the energy absorption at the occurrence of local damage $\left(E_{\text {curr }}\right)$ to the total energy absorption at the end of the test $\left(E_{\text {total }}\right)$ as given in Equation 2:

$$
\hat{E}=E_{\text {curr }} / E_{\text {total }}
$$

The damage functions given in Equations 1 and 2 were used for monotonically loaded specimens to quantify the damage at each limit state. In the case of cyclically loaded specimens, the amount of damage was calculated using the back-bone curves of the hysteretic response. The damage function of cyclically loaded specimens $\left(\hat{E}^{c}\right)$ given in Equation 3 was defined as the ratio of the area under the cyclic back-bone curve until the point at which damage is assessed $\left(E_{c b}\right)$ to the area under the complete cyclic back-bone curve $\left(E_{m}\right)$. In Equation 3, it was assumed that the value of the damage function at both directions of loading is the same due to the symmetry typically seen in RCFT response.

$$
\hat{E}^{c}=\frac{E_{c b}}{E_{m}}
$$

For the specimens included in the experimental database, the damage functions were evaluated at each local damage level. The damage function values were then correlated to the material and geometrical properties of the RCFT members (e.g., D/t, $\left.f_{y}, f^{\prime}{ }_{c}\right)$. This resulted in equations to estimate the damage function values at the occurrence of local damage levels defined for the RCFT members. The displacement-based damage function values define the damage with respect to the 
attainment of peak load capacity. Therefore, it does not give an indication about the reserve capacity of the specimens. On the other hand, the energy-based damage function values identify the amount damage relative to the point of failure (Tort and Hajjar, 2004). Thus, it is possible to assess the proximity of the specimens to failure. However, the energy-based damage function values alone are not adequate to evaluate the remaining strength of the specimens following the occurrence of local damage. In this research, equations were also correlated to calculated ductilities from the experiments (with the specific ductility definition depending on the type of experiment) so as to quantify the available ductility of RCFT specimens to supplement the energy-based and displacement-based damage function equations. For example, Equation 4 is the ductility function $(\kappa)$ derived for RCFT beam-column specimens that are fixed at each end, subjected to constant axial compression, and subjected to shear to put the member in double curvature:

$$
\kappa=-0.32 \times(L / D)-3.78 \times\left(P_{c} / P_{o}\right)-0.28 \times\left(P / P_{o}\right)+23.24
$$

where $P$ is the axial compression force; $P_{c}$ is the nominal strength of concrete; and $P_{o}$ is the nominal strength of composite section.

The damage function and ductility function equations together may be used to assess the local capacity of RCFT members at multiple limit states. In this paper, for brevity, the damage assessment study is presented only for beam-column specimens. The damage assessment studies of the remaining RCFT member and connection types may be found in Tort and Hajjar (2003).

\section{Monotonically Loaded Beam-Columns}

The monotonically-loaded beam-column specimens recorded in the database were studied in distinct groups depending on the type of loading (Tort and Hajjar, 2003). For brevity, the beam-column specimens that were tested under constant axial compression $(P)$ and monotonically increasing shear force $(V)$ will be presented.

The local damage levels reported in the beam-column tests were yielding of compression flange (YCF), yielding of tension flange (YTF), local buckling in the compression flange (LBF), and local buckling in the web (LBW). These damage levels were detected by direct assessment of the load-deflection curves. Concrete cracking and concrete crushing local damage levels could not be determined accurately from the experiments in the database and were thus assessed based upon simple analytical procedures as discussed in Tort and Hajjar (2003). The YTF damage level is discussed below as an example of the available results.

Equation 5 was derived to estimate the displacement-based damage function values at the initiation of YTF $\left(d_{t y} / d_{o}\right)$ :

$$
\frac{d_{t y}}{d_{o}}=1.47 \frac{P}{P_{o}}-5.28 \frac{P_{s}}{P_{o}}+3.85
$$


where $P$ is the axial compression force; $P_{s}$ is the nominal strength of steel tube. As can be noticed from Equation 5, the experimental results indicated that the specimens having a high axial load ratios (i.e., high $P / P_{o}$ ) experienced the YTF damage level at later stages of loading compared to the ones with low axial load ratios. In addition, it was also found that if the specimens have a large steel ratio (i.e., large $P_{s} / P_{o}$ ), the steel tube takes a larger share of the load, causing the YTF damage level to take place earlier. A similar trend was also obtained for the energy-based damage function at YTF damage level $\left(E_{t y} / E_{\text {total }}\right)$. Figure 1 illustrates the variation of $E_{t y} / E_{\text {total }}$ with respect to the parameters of $P / P_{o}$ and $D / t$. It is evident from Figure 1 that the specimens having a high axial load ratio (i.e., high $P / P_{o}$ ) experience the YTF damage level later than specimens with a large steel ratio (i.e., large $D / t$ or large $\left.P_{s} / P_{o}\right)$. In Figure 1, the damage function values were presented with the available ductility of the specimens, showing that the beam-columns have a large deformation capacity without significant reduction in strength, particularly when YTF occurs earlier in the loading history.

A summary of the deformation-based and energy-based damage functions including their limits of applicability (e.g., $f_{y}, f^{\prime}{ }_{c}, D / t$ ) and statistical properties [number of data points $(N)$, coefficient of correlation $\left(R^{2}\right)$, mean value $(\eta)$, standard deviation $\left.(\sigma)\right]$ can be seen in Table 1. Similar tables were developed for the other member types covered in the experimental database and may be found in Tort and Hajjar (2003).

\section{Cyclically Loaded Beam-Columns}

The cyclically-loaded beam-columns in the database that are presented in this paper were tested under constant axial load and cyclically applied shear loading at the free end. Local damage levels similar to those of monotonically loaded beamcolumns were observed. The energy-based damage function given in Equation 3 was utilized for damage assessment. As an example of the damage assessment for cyclically loaded beam-columns, the LBF local damage level is discussed below.

In Figure 2, the energy-based damage index at $\operatorname{LBF}\left(E_{l b f} / E_{m}\right)$ is plotted with

respect to the parameter $(D / t) \times \sqrt{f_{y} / E_{s}}$. The results were presented for two groups based on the axial load ratios. It was found that for both low and high axial ratios, $E_{l b f} / E_{m}$ exhibits a decreasing trend for increasing values of $(D / t) \times \sqrt{f_{y} / E_{s}}$. However, no trend of $E_{l b f} / E_{m}$ was observed with respect to the level of axial load.

\section{Parametric Study}

The range of damage function values attained by RCFT members was investigated by performing a parametric study of the proposed damage function equations. This was achieved by generating multiple RCFT specimens through varying their structural parameters within the ranges where the damage function 
equations are applicable. The damage function values corresponding to each local damage level were then evaluated and the resulting damage function values were all plotted on the same graph. This allowed comparison of the sequence of occurrence of local damage in the RCFT members and connections.

For example, a parametric study of RCFT beam-columns tested under constant axial load and monotonically increasing shear load at the ends was performed by varying the structural properties of $D / t, L / D, f^{\prime}{ }_{c}$ and $f_{y}$. A total of sixteen specimens were generated and for each specimen the damage index and ductility values were evaluated. Figure 3 presents the result of the parametric study for the energy-based damage function of RCFT beam-columns. If the sequence of local damage levels is compared, an intricate relation between the damage states may be observed depending on the properties of the RCFTs (not presented here for brevity). For example, lower ductility is clearly exhibited for members in which local buckling of the steel tube web occurs prior to yielding of the steel tube flange. With the composite action occurring between the constituent materials, the relationship of which RCFTs will achieve good ductility is complex, as seen in Figures 1 and 2.

Based on the ranges of the damage function values, it is possible to correlate the local damage states into performance levels. For example, in the case of monotonically loaded beam-columns, LBW often has damage function values between 0.30 and 0.45 . These may be associated with a life safety performance level, as local buckling should be avoided for low levels of loading. However, LBW has damage index values ranging from 0.30 to 0.70 for cyclically loaded beam-columns, such that it is appropriate to associate LBW with either the life safety or near collapse damage levels. Thus, the complex interactions seen between the damage states due to the composite interaction of the member mean that a single local damage state must often be associated with different performance levels depending on the specific material and geometric properties of the RCFT member. Similar categorizations were made for all the damage levels for monotonically- and cyclically loaded RCFTs members and connections in Tort and Hajjar (2003, 2004).

\section{Capacity Assessment at the Global Level}

In PBD, the acceptance criteria for the intended performance-objectives are often checked both at the local and global level (Krawinkler, 1999). In contrast to the capacity of structural components that is commonly determined from experimental tests, the capacity of structural systems is usually calculated using parametric analysis methods utilizing nonlinear time history analysis (e.g., Vamvatsikos and Cornell, 2002; Ibarra, 2003). In this research, a non-linear fiber-based finite element formulation of RCFT beam-columns was formulated to be used for non-linear dynamic analysis of RCFT frames. The formulation was implemented with new steel and concrete uniaxial constitutive rules accounting for the salient features of RCFTs. 


\section{Finite Element Formulation}

In prior work, a 3D beam-column finite element formulation was developed to analyze frame structures having steel girders framing into RCFT columns (Hajjar et al., 1998). The beam-column finite element formulation was implemented in a general structural analysis program allowing both geometrically and materially nonlinear analysis of RCFT frames. The slip between the steel tube and concrete core was accounted for by defining separate translational degrees-of-freedom for the steel tube and concrete core. The rotational degrees-of-freedom defined for the steel tube and concrete were assumed to be the same. Penalty constraints were defined between the shear translational degrees of freedom of steel tube and concrete core. Therefore, the steel tube and concrete core exhibit differential movement with respect to each other only in the axial direction (Hajjar et al., 1998). A distributed plasticity approach was adopted to account for material nonlinear effects. The element ends were discretized into individual steel and concrete fibers. Throughout the analysis, the stress and strain response of each fiber is tracked. In this research, the formulation was reworked as a mixed finite element formulation to calculate the internal element forces using a Hellinger-Reissner two-field variational formulation following the work by Alemdar (2001).

\section{Concrete Constitutive Model}

The uniaxial concrete stress-strain model developed by Chang and Mander (1994) is implemented in this research. The stress-strain response was simulated by a family of curves represented by polynomial expressions. Three types of curves were introduced, including envelope curves, connecting curves, and transition curves. Envelope curves define the boundaries of the hysteretic response. Different envelope curves are derived for the tensile and compressive response of concrete. Connecting curves identify the rule to connect envelope curves. Any strain reversal requires shifting from the current connecting curve to the one going in the opposite direction. The rule for this process is defined by the transition curves.

In this research, the envelope curve in compression proposed by Chang and Mander (1994) was modified to account for the typical characteristics of RCFT members. No enhancement in concrete strength due to confinement was accounted for. A plain concrete response was assumed until the compressive strength is attained and the stress-strain response in the pre-peak region was adopted from Collins and Mitchell (1991). The post-peak response of the envelope curve was assumed to have linear strength degradation region followed by constant strength response at large strain levels. The strength degradation and constant strength regions were characterized by the parameters of $K_{c}$ and $f_{r c}$, respectively. $K_{c}$ is the slope of strength degradation region and $f_{r c}$ is the residual strength of concrete at high strain levels. Equations 6 and 7 were proposed to calculate $K_{c}$ and $f_{r c}$, respectively. These equations were derived from the stress-strain data provided by Sakino and Yuping (1994) and Varma (2000). The $R^{2}$ values of $K_{c}$ and $f_{r c}$ were determined to be 0.73 and 0.68 , respectively: 


$$
\begin{aligned}
& \frac{K_{c}}{f^{\prime}{ }_{c}}=332.75 \times R-9.60 \text { and } \\
& \frac{f_{r c}}{f^{\prime}{ }_{c}}=0.32 \times R^{-0.5} \text { where } R=\frac{D}{t} \sqrt{\frac{f_{y}}{E_{s}}} \frac{f_{c}^{\prime}}{f_{y}}
\end{aligned}
$$

The connecting curves, transition curves, and the tensile envelope curve proposed by Chang and Mander (1994) were kept unchanged for RCFT specimens.

\section{Steel Constitutive Model}

The stress-strain response of steel tube was simulated through a uniaxial bounding surface plasticity model developed by Mizuno et al. (1992). The original model was modified to account for the local buckling effect of the steel tube. It was assumed that steel undergoes a linear strength degradation region once local buckling strain level is attained. Similar to the envelope curve of concrete, following the strength degradation response, a constant strength region is maintained. The strain level at initiation of local buckling $\left(\varepsilon_{l b f}\right)$ was determined from the experimental results

of axially load RCFT columns tests. Equation 8 provides $\varepsilon_{l b f}$ as a fraction of yield strain $\left(\varepsilon_{y}\right)$. The $R^{2}$ of Equation 8 was calculated as 0.61 :

$$
\frac{\varepsilon_{l b f}}{\varepsilon_{y}}=3.14 \times\left(\frac{D}{t} \sqrt{\frac{f_{y}}{E_{s}}}\right)^{-1.48}
$$

The parameters defining the response of the steel after local buckling were defined to be slope of strength degradation region $\left(K_{s}\right)$ and the residual strength at high strain levels $\left(f_{r s}\right)$. These parameters were determined through a calibration study performed on axially loaded RCFT specimens with wide ranges of material strength and geometric properties. Equations 9 and 10 were derived to estimate $K_{s}$ and $f_{r s}$. The values of $R^{2}$ for Equation 9 and 10 were found to be 0.85 and 0.64 , respectively.

$$
\begin{aligned}
& \frac{K_{s}}{f_{y}}=0, \frac{D}{t} \times \frac{f_{y}}{E_{s}} \leq 0.08 \text { and } \frac{K_{s}}{f_{y}}=1033.50 \times \frac{D}{t} \times \frac{f_{y}}{E_{s}}-86.32, \frac{D}{t} \times \frac{f_{y}}{E_{s}} \geq 0.08 \\
& \frac{f_{\text {res }}}{f_{y}}=1, \frac{D}{t} \times \frac{f_{y}}{E_{s}} \leq 0.08 \text { and } \frac{f_{\text {res }}}{f_{y}}=-7.31 \times \frac{D}{t} \times \frac{f_{y}}{E_{s}}+1.58, \frac{D}{t} \times \frac{f_{y}}{E_{s}} \geq 0.08
\end{aligned}
$$

\section{Verification of RCFT Fiber-Element Formulation}

Two sets of analyses were performed to verify the fiber-element formulation for RCFT beam-columns having a wide range of properties and subjected to monotonic loading. Ongoing research continues verification of the performance for cyclic loading prior to engaging in parametric studies to assess global capacity and seismic demand of suite of RCFT frame structures.

In the first verification set, RCFT columns tested under eccentrically applied loading were studied. RCFT beam-column specimens tested by Bridge (1976), Shakir-Khalil 
and Zeghiche (1989), and Cederwall et al. (1990) were analyzed, typically using two to four elements along the length of the member, with comparisons shown in Figure 4. These specimens, including $1,1^{*}, 2,7,10$, and 13 , have values, respectively, of $D / t$ (depth/thickness $)=24,20,24,24,15,15 ; L / D($ length/depth $)=27,10,23,23,27$, $27 ; f_{c}=6.8,4.3,5.8,6.4,5.6,11.6 \mathrm{ksi} ; f_{y}=44,42,56,52,55,53 \mathrm{ksi}$. The second set of specimens was selected from experiments where RCFT beam-columns were tested under constant axial load and monotonically increasing bending moment, putting the member into single curvature. Specimens from Tomii and Sakino (1979), Varma (2000), and Nakahara and Sakino (1998) were analyzed. In Figure 5, these specimens, including BC328020, BC484622, BR4-3-10-02, BR4-3-10-02, BR8-6-1002, III-2, and III-5 (shown left to right in the figure) have values, respectively, of $D / t$ $($ depth/thickness $)=34,52,63,31,33,33 ; L / D($ length/depth $)=5,5,3,3,3,3 ; f_{c}=$ $16.0,16.0,17.3,17.3,3.0,3.0 \mathrm{ksi} ; f_{y}=81.2,68.3,45.0,113.3,42.0,42.0 \mathrm{ksi} ; P / P_{o}=$ $0.21,0.22,0.20,0.20,0.20,0.50$.

\section{Conclusions}

This paper presents the evaluation of local capacity of RCFT members. In addition, a fully nonlinear analysis model to be used in global capacity and demand assessment of RCFT frames was reported. The main conclusions are listed below:

1. The local damage types recorded in the experimental database developed in this work document the progression of damage for the damage states to be considered in performance-based design of RCFT members

2. The proposed displacement and energy-based damage functions provided an efficient way of to quantify the capacity of RCFT members.

3. The damage function values were correlated versus parameters representing the composite nature of RCFT members.

4. Complex interactions were seen between the damage states due to the composite interaction of the member, with some damage states occurring either earlier or later than others depending on the material and geometric properties of the RCFT. Thus, a single local damage state must often be associated with different performance levels depending on the RCFT properties.

5. The stress-strain relationships derived for the steel tube and concrete core were able to account for the effects local buckling of the steel tube and confinement of the concrete. Accurate analysis results of RCFT members were obtained for wide ranges material strengths and geometric dimensions. Ongoing research is documenting the global capacity and demand of a suite of RCFT frames to complete the development of the RCFT performance-based design methodology.

\section{Acknowledgements}

This research was funded by the National Science Foundation (Grant No. CMS-0084848) and by the University of Minnesota. Any opinions, findings, and conclusions or recommendations expressed in this material are those of the authors and do not necessarily reflect the views of the National Science Foundation. 


\section{References}

Alemdar, B.N., (2001). "Distributed Plasticity Analysis of Steel Building Structural Systems," Ph.D. diss., Dept. of Civil Engr., GA Inst. of Tech., Atlanta, GA.

Bridge, R. Q. (1976). "Concrete Filled Steel Tubular Columns," Report No. R283, School of Civil Engineering, University of Sydney, Sydney, Australia.

Cederwall, K., Engstrom, B., and Grauers, M. (1990). "High Strength Concrete Used in Composite Columns," 2nd Intl. Symp. on Util. of High-Str. Conc., ACI, Detroit, MI, 195-214.

Chang, G. A. and Mander, J. B. (1994). "Seismic Energy Based Fatigue Damage Analysis of Bridge Columns: Part I - Evaluation of Seismic Capacity." Report No. NCEER-94-0006, Natl. Cen. for Earthq. Engr. Res., SUNY, Buffalo, NY.

Collins, M. P. and Mitchell, D. (1991). Prestressed Concrete Structures, PrenticeHall, Englewood Cliffs, New Jersey.

Hajjar, J. F., Molodan, A., and Schiller, P. H. (1998). "A Distributed Plasticity Model for Cyclic Analysis of Concrete-Filled Steel Tube Beam-Columns and Composite Frames," Engr. Struc., 20, (4-6), April-June, 398-412.

Ibarra, L. F., (2003). "Global Collapse of Frame Structures Under Seismic Excitations," Ph.D. diss., Dept. of Civil Eng., Stanford Univ,, Stanford, CA.

Mizuno, E., Shen, C., Tanaka, Y., and Usami, T. (1992). "A Uniaxial Stress-Strain Model for Structural Steels under Cyclic Loading," Stability and Ductility of Steel Structures Steels under Cyclic Loading, Fukumoto, Y. and Lee, G. C. (eds.), CRC Press, Boca Raton, FL, 37-48.

Moehle, J. and Deierlein, G. G. (2004). "A Framework Methodology for Performance-Based Earthquake Engineering," Paper No. 679, Proc., $13^{\text {th }}$ World Conf. on Earthq. Engr., Vancouver, BC, Canada, August 1-6, 2004.

Nakahara, H. and Sakino, K. (1998). "Axial Compressive and Uniform Bending Tests of High Strength Concrete Filled Square Steel Tubular Columns," Proc., Fifth Pacific Struc. Steel Conf., Seoul, Korea, Oct. 13-16, 1998, 943-948.

Sakino, K. and Yuping, S. (1994). "Stress-Strain Curve of Concrete Confined by Rectilinear Hoop," J. of Struc. Constr. Engr., AIJ, No. 461, July, 95-104.

Shakir-Khalil, H. and Zeghiche, Z. (1989). "Experimental Behavior of ConcreteFilled Rolled Rectangular Hollow-Section Columns," The Struc. Eng., 67(19), 345-353.

Tomii, M. and Sakino, K. (1979). "Experimental Studies on the Ultimate Moment of Concrete Filled Square Steel Tubular Beam-Columns," Trans. of the AIJ, No. 275, January, 55-63.

Tort, C. and Hajjar, J. F. (2003). "Damage Assessment of Concrete-Filled Steel Tube Members and Frames," Report ST-03-1, Dept. of Civil Eng., Univ. of MN, Minneapolis, MN.

Tort, C. and Hajjar, J. F. (2004). "Damage Assessment of Rectangular ConcreteFilled Steel Tubes for Performance-Based Design," Earthq. Spectra, in press.

Vamvatsikos, D. and Cornell, C., A. (2002). "Incremental Dynamic Analysis," Earthq. Engr. and Struc. Dyn., 31, 491-514.

Varma, A. H. (2000). "Seismic Behavior, Analysis, and Design of High Strength Square Concrete Filled Steel Tube (CFT) Columns," Ph.D. diss., Dept. of Civil Eng., Lehigh Univ., Bethlehem, PA. 

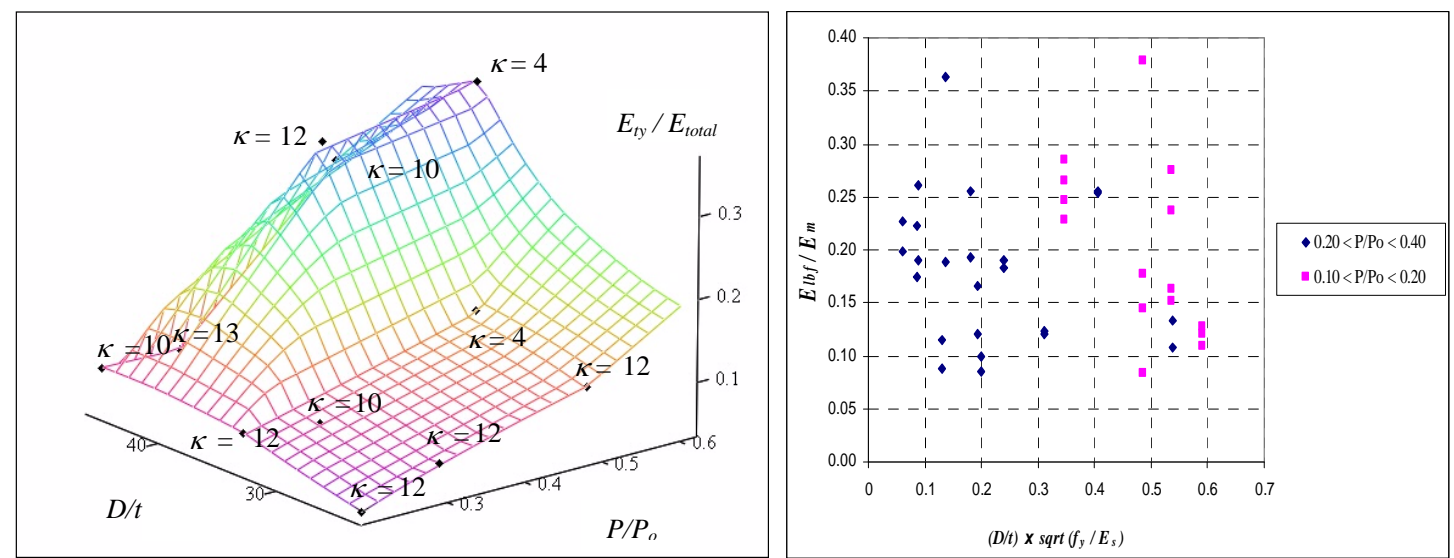

Figure 1. $D / t$ and $P / P_{o}$ vs. $E_{t y} / E_{\text {total }}$ monotonically-loaded beam-columns

Figure 2. $D / t \sqrt{f_{y} / E_{s}}$ vs. $\boldsymbol{E}_{l b f} / \boldsymbol{E}$ for for cyclically-loaded beam-columns

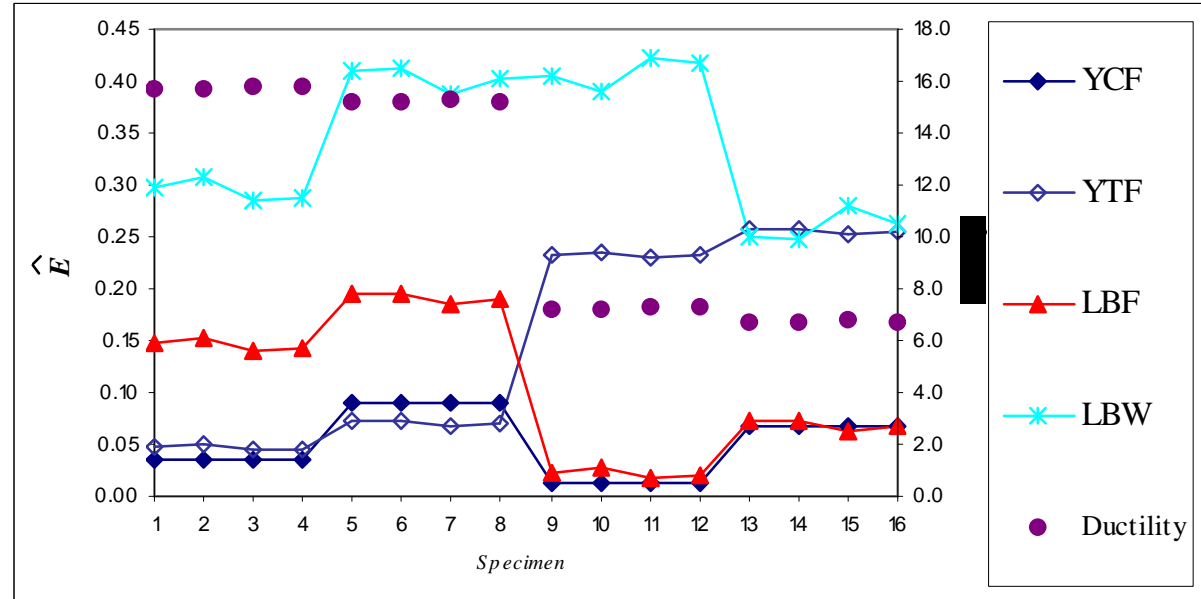

Figure 3. Comparison of energy-based damage indices for monotonically-loaded beam-column tests

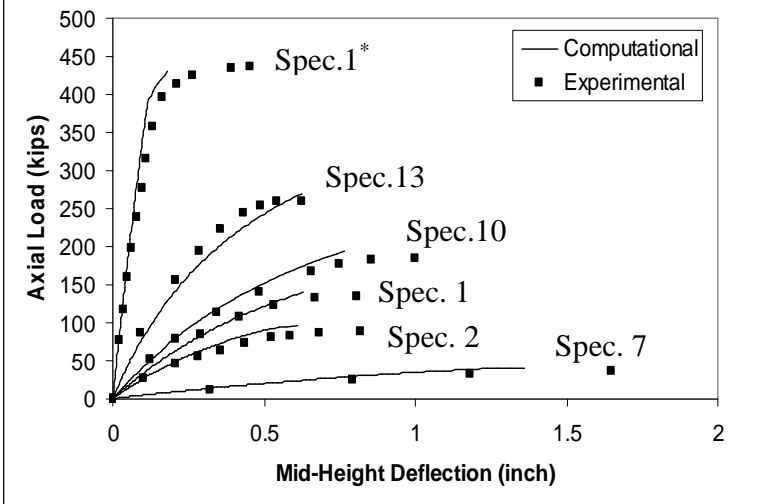

Figure 4. Comparison of results for proportionally-loaded RCFT RCFT beam-columns

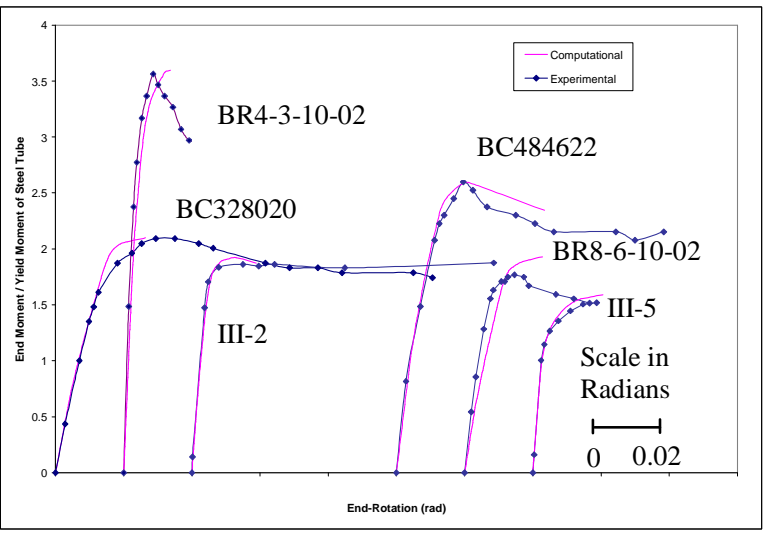

Figure 5. Comparison of results for non-proportionally-loaded beam-columns 
Table 1: Damage Index Equations for Monotonically-Loaded Beam-Columns

\begin{tabular}{|c|c|c|c|}
\hline Damage Type & Damage Index Equation & $\begin{array}{c}\text { Range of Parameters } \\
{\left[P / P_{o} ; L / D ; D / t ; f_{c}^{\prime} ; f_{y} ; P_{c} / P_{o}\right]}\end{array}$ & $\begin{array}{l}\text { Statistics } \\
{\left[N ; R^{2} ; \eta ; \sigma\right]}\end{array}$ \\
\hline \multirow[b]{2}{*}{$\begin{array}{l}\text { Yielding of } \\
\text { Compression } \\
\text { Flange }\end{array}$} & $\frac{d_{c y}}{d_{o}}=-1.60 \frac{P}{P_{o}}-2.47 \frac{P_{s}}{P_{o}}+2.64$ & $\begin{array}{c}{[0.20-0.50 ; 3.0 ; 23.5-45.4 ; 20.5-22.1 ; 290.4-} \\
315.9 ; 0.26-0.43]\end{array}$ & {$[9 ; 0.74 ; 0.51 ; 0.29]$} \\
\hline & $\frac{E_{c y}}{E_{\text {total }}}=0.068 \frac{D}{t} \sqrt{\frac{f_{y}}{E_{s}}}-0.073 \frac{P}{P_{o}}-0.014$ & $\begin{array}{c}{[0.20-0.50 ; 3.0 ; 23.5-45.4 ; 20.5-22.1 ; 290.4-} \\
315.9 ; 0.26-0.43] \\
\frac{D}{t} \sqrt{\frac{F_{y}}{E_{s}}}: 0.94-1.73\end{array}$ & $\begin{array}{l}{[9 ; 0.51 ; 0.68 ;} \\
0.032]\end{array}$ \\
\hline \multirow{2}{*}{$\begin{array}{l}\text { Yielding of } \\
\text { Tension } \\
\text { Flange }\end{array}$} & $\frac{d_{t y}}{d_{o}}=1.47 \frac{P}{P_{o}}-5.28 \frac{P_{s}}{P_{o}}+3.85$ & $\begin{array}{c}{[0.20-0.61 ; 3.0 ; 23.5-45.4 ; 20.5-22.1 ; 290.4-} \\
315.9 ; 0.26-0.43]\end{array}$ & $\begin{array}{l}{[11 ; 0.70 ; 0.94 ;} \\
0.46]\end{array}$ \\
\hline & $\frac{E_{t y}}{E_{\text {total }}}=0.62 \frac{P}{P_{o}}-0.16 \frac{P_{s}}{P_{o}}+0.039$ & $\begin{array}{c}{[0.20-0.61 ; 3.0 ; 23.5-45.4 ; 20.5-22.1 ; 290.4-} \\
315.9 ; 0.26-0.43]\end{array}$ & $\begin{array}{l}{[11 ; 0.60 ; 0.15 ;} \\
0.11]\end{array}$ \\
\hline \multirow{2}{*}{$\begin{array}{l}\text { Local } \\
\text { Buckling of } \\
\text { Compression } \\
\text { Flange }\end{array}$} & $\frac{d_{l b f}}{d_{o}}=-3.68 \frac{P}{P_{o}}-3.11 \frac{P_{s}}{P_{o}}+3.97$ & $\begin{array}{c}{[0.00-0.52 ; 1.0-3.0 ; 23.5-45.4 ; 20.5-45.3 ;} \\
194.2-315.8 ; 0.30-0.74]\end{array}$ & $\begin{array}{l}{[32 ; 0.42 ; 1.00} \\
0.92]\end{array}$ \\
\hline & $\frac{E_{l b f}}{E_{\text {total }}}=-0.41 \frac{P}{P_{o}}-0.32 \frac{P_{s}}{P_{o}}+0.46$ & $\begin{array}{c}{[0.00-0.52 ; 2.0-6.0 ; 23.5-45.4 ; 20.5-45.3 ;} \\
194.2-315.8 ; 0.30-0.74]\end{array}$ & $\begin{array}{l}{[32 ; 0.41 ; 0.12 ;} \\
0.097]\end{array}$ \\
\hline \multirow{3}{*}{$\begin{array}{l}\text { Local } \\
\text { Buckling of } \\
\text { Steel Tube } \\
\text { Web }\end{array}$} & $\frac{d_{l b w}}{d_{o}}=-4.81 \frac{P}{P_{o}}-10.49 \frac{P_{s}}{P_{o}}+10.81$ & $\begin{array}{c}{[0.20-0.50 ; 3.0 ; 23.5-45.4 ; 20.5-22.1 ; 290.4-} \\
315.9 ; 0.26-0.43]\end{array}$ & {$[9 ; 0.62 ; 2.43 ; 1.24]$} \\
\hline & $\begin{array}{c}\text { for } P / P_{o} \geq 0.50 \\
\frac{E_{\text {lbw }}}{E_{\text {total }}}=1.03 \frac{P_{s}}{P_{o}}-0.34\end{array}$ & $\begin{array}{c}{[0.50 ; 3.0 ; 23.5-45.4 ; 20.5-22.1 ; 290.4-315.9 ;} \\
0.26-0.43]\end{array}$ & $\begin{array}{l}{[3 ; 0.90 ; 0.32 ;} \\
\quad 0.090]\end{array}$ \\
\hline & $\begin{array}{c}\text { for } P / P_{o}<0.50 \\
\frac{E_{\text {lbw }}}{E_{\text {to tal }}}=-0.75 \frac{P_{s}}{P_{o}}+0.84\end{array}$ & $\begin{array}{c}{[0.20-0.30 ; 3.0 ; 23.5-45.4 ; 20.5-22.1 ; 290.4-} \\
315.9 ; 0.26-0.43]\end{array}$ & $\begin{array}{l}{[5 ; 0.59 ; 0.35 ;} \\
\quad 0.080]\end{array}$ \\
\hline
\end{tabular}

